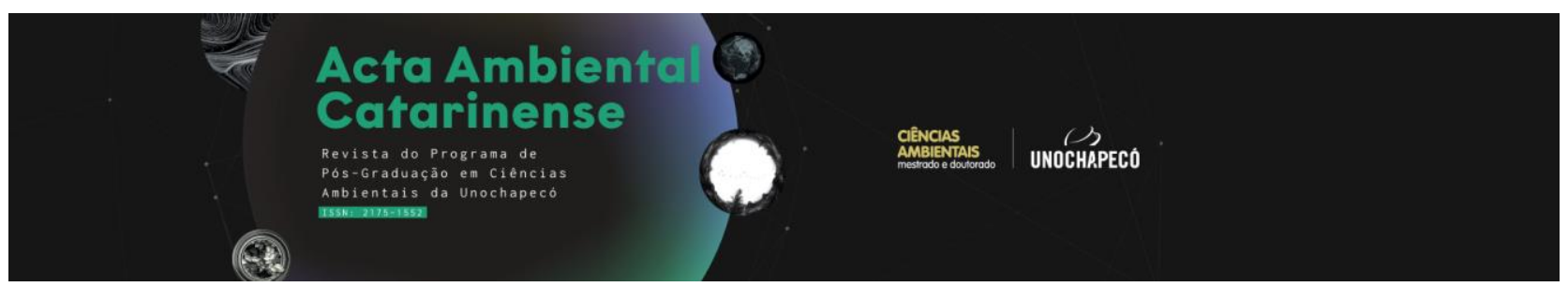

\title{
COMPOSIÇÃO DA ICTIOFAUNA DO CÓRREGO BEBEDOURO (FRUTAL, MG) E SUA RELAÇÃO COM FATORES AMBIENTAIS
}

\author{
Júlio Cesar dos Santos Lima ${ }^{1}$ \\ Renata Cassemiro Biagioni ${ }^{2}$ \\ Cristiano Pereira da Cunha ${ }^{2}$ \\ Vitor Loreno de Almeida Cerqueira ${ }^{3}$ \\ Ariane Almeida $\mathrm{Vaz}^{4}$ \\ Adriane Almeida $\mathrm{Vaz}^{4}$ \\ Cleber Coelho Machado ${ }^{4}$ \\ Sofia Luiza Brito ${ }^{5}$ \\ Tânia Aparecida Silva Brito ${ }^{6}$ \\ Welber Senteio Smith ${ }^{4}$
}

\begin{abstract}
Resumo
A ictiofauna de riachos na região Neotropical ainda não é totalmente conhecida, sendo dados sobre a composição e distribuição de espécies incipientes. Este estudo objetivou investigar a composição da ictiofauna do córrego Bebedouro (Frutal - MG), de forma a contribuir no conhecimento da riqueza e distribuição de espécies no sudeste do Brasil. As amostragens foram realizadas no período seco (setembro/2012) e no período chuvoso (março de 2013), utilizando diferentes técnicas de pesca, em três trechos do córrego caracterizados quanto a diferentes parâmetros ambientais, limnológicos e de estrutura de habitat. Foram capturados 677 indivíduos de 50 espécies (45 são nativas e cinco não-nativas) distribuídas em seis ordens, sendo 239 no período chuvoso e 438 no período seco. As abundâncias das espécies entre os trechos em um mesmo período e entre os períodos não apresentaram diferenças significativas. A análise do protocolo de avaliação aplicado salientou que o córrego apresenta trechos com características de impacto antrópicos e naturais. Nossa hipótese de que a composição da comunidade de peixes não é homogênea ao longo dos trechos amostrados foi confirmada e observamos que a complexidade das espécies aumenta dos trechos à montante em direção à jusante.
\end{abstract}

Palavras-chave: Peixes, Região Neotropical, Variáveis ambientais, Variação sazonal.

\footnotetext{
${ }^{1}$ Escola de Engenharia de São Carlos - Universidade de São Paulo (USP). E-mail: jcslima1982@usp.br.

${ }^{2}$ Universidade Federal de São Carlos (UFSCar).

${ }^{3}$ Secretaria de Meio Ambiente e Turismo de Anapu/PA.

${ }^{4}$ Universidade Paulista (UNIP).

${ }^{5}$ Universidade do Estado de Minas Gerais (UEMG), Unidade Ubá.

${ }^{6}$ Centro Internacional de Água e Transdisciplinaridade (CIRAT). 


\title{
COMPOSITION OF THE ICHTHYOFAUNA AT BEBEDOURO STREAM (FRUTAL, MG) AND ITS RELATIONSHIP WITH ENVIRONMENTAL FACTORS
}

\begin{abstract}
The ichthyofauna of streams in the Neotropical region is not yet fully known, with data on the composition and distribution of incipient species. This study aimed to investigate the composition of the ichthyofauna of the Bebedouro stream (Frutal - MG), in order to contribute to the knowledge of species richness and distribution in southeastern Brazil. Sampling was carried out in the dry period (September / 2012) and in the rainy period (March 2013), using different fishing techniques, in three stretches of the stream characterized by different environmental, limnological and habitat structure parameters. 677 individuals of 50 species were captured (45 are native and five non-native) distributed in six orders, 239 in the rainy season and 438 in the dry season. The abundances of species between stretches in the same period and between periods did not show significant differences. The analysis of the applied evaluation protocol highlighted that the stream has stretches with anthropic and natural impact characteristics. Our hypothesis that the composition of the fish community is not homogeneous throughout the sampled stretches was confirmed and we observed that the complexity of the species increases from upstream to downstream areas.
\end{abstract}

Keywords: Pisces. Neotropical region. Environmental variables. Seasonal variation.

\section{INTRODUÇÃO}

Os ambientes aquáticos de água doce constituem os ecossistemas mais ameaçados do planeta devido principalmente aos impactos antrópicos negativos, que além de desestabilizarem seu funcionamento, comprometem toda a biodiversidade neles presente (FREDERICO et al., 2018). É estimado que a taxa de extinção de organismos aquáticos de água doce seja até cinco vezes maior em relação a taxa de extinção dos organismos terrestres (RICCIARDI e RASMUSSEN, 1999), pois, mesmo perfazendo menos de $0,3 \%$ de toda água presente na superfície da Terra, esses ambientes comportam mais de 15 mil espécies de peixes, representando $40 \%$ de todos os peixes encontrados no planeta e $25 \%$ de todos os vertebrados (REIS et al., 2016). Na região Neotropical encontra-se a maior diversidade de peixes com cerca de 6.255 espécies conhecidas (BIRINDELLI e SIDLAUSKAS, 2018), sendo 3.200 no Brasil e, embora seja o país que concentre o maior número de espécies de peixes (DIAS et al., 2016), as informações sobre a biologia básica, taxonomia, sistemática e história natural da ictiofauna de rios, córregos e riachos do país ainda são incipientes (REIS et al., 2016).

Os córregos e riachos possuem características físicas e biológicas distintas ao longo do gradiente longitudinal, apresentando aumento na heterogeneidade do ambiente no sentido montante-jusante (VIEIRA et al., 2018). Esses ambientes vêm atraindo a atenção de ictiólogos por representarem uma importante fonte de novas espécies de peixes, principalmente na região Neotropical (DIAS et al., 2016), entretanto, nessa região esses organismos são afetados pelas variações sazonais (período seco e chuvoso) que propiciam a expansão e retração de seus habitats, podendo criar ou eliminar microhabitats (MELO et al., 2003), como por exemplo, chuvas intensas que podem promover o aumento do fluxo de água, produzindo um aporte de materiais orgânicos e inorgânicos, além da conformação do leito e o carregamento da biota (LUIZ et al., 1998). 
GERHARD et al. (2004) afirmam que as características locais do ambiente, como o grau de sombreamento, a vegetação marginal e a turbidez da água, assim como características regionais como latitude, posição da área de drenagem e ordem do rio, também atuam como fatores controladores da composição das comunidades de peixes.

Nestes sistemas, as comunidades de peixes são, em sua grande maioria, de pequeno porte com alto grau de endemismo e estima-se que estes representem mais de $50 \%$ de todas as espécies de peixes de água doce da região Neotropical (MARCENIUK et al., 2011). Estes apresentam menor capacidade de locomoção, quando comparada à espécies de grande porte da mesma região, sendo isso uma das principais causas da distribuição geográfica mais restrita das espécies de peixes de ambientes aquáticos de baixa ordem, assim como as características geográficas e a história geológica local, que também contribuem significativamente para a destacada diversidade de peixes (THOMAZ e KNOWLES, 2018). Contudo, os córregos podem ser facilmente alterados pela interferência humana (FERREIRA e CASATTI, 2006), podendo existir diversas espécies sob risco de extinção sem ao menos terem sido descritas ou estudadas (FREDERICO et al., 2018; GONÇALVES e CESTARI, 2018).

Nesse sentido, este estudo objetivou investigar a composição da ictiofauna do córrego Bebedouro (Frutal, Minas Gerais), através do conhecimento da abundância, riqueza, diversidade e constância de espécies provenientes de diferentes trechos amostrados do córrego, analisando a sua distribuição temporal e espacial, verificando a relação entre a riqueza, a diversidade e abundância de espécies com algumas variáveis físicas, químicas e biológicas da água. Nossa hipótese é que a estrutura da comunidade de peixes difere ao longo dos trechos amostrados e que a complexidade das espécies aumentara de áreas à montante em direção à jusante.

\section{Material e Métodos}

As amostragens da ictiofauna foram realizadas em oito pontos no córrego Bebedouro localizado no município de Frutal, Minas Gerais, sendo dois pontos distribuídos no trecho alto $\left(20^{\circ} 00 ' 24^{\prime \prime} \mathrm{S}\right.$ e $\left.49^{\circ} 00^{\prime} 17^{\prime \prime} \mathrm{W}\right)$, três pontos no trecho médio $\left(20^{\circ} 01^{\prime} 51^{\prime \prime} \mathrm{S}\right.$ e $48^{\circ} 59^{\prime} 54^{\prime \prime}$ W) e três na foz $\left(20^{\circ} 04^{\prime} 05^{\prime \prime} \mathrm{S}\right.$ e $49^{\circ} 00^{\prime} 61^{\prime}$ W) (Figura 1). A bacia do córrego Bebedouro possui $124,2 \mathrm{~km}^{2}$ e se une ao Ribeirão Frutal que desaguam no reservatório de Marimbondo (EMATER - MG e CENEP, 2004). O córrego Bebedouro é de quarta ordem e está situado na transição entre a planície e o planalto do rio Grande (STRAHLER, 1952).

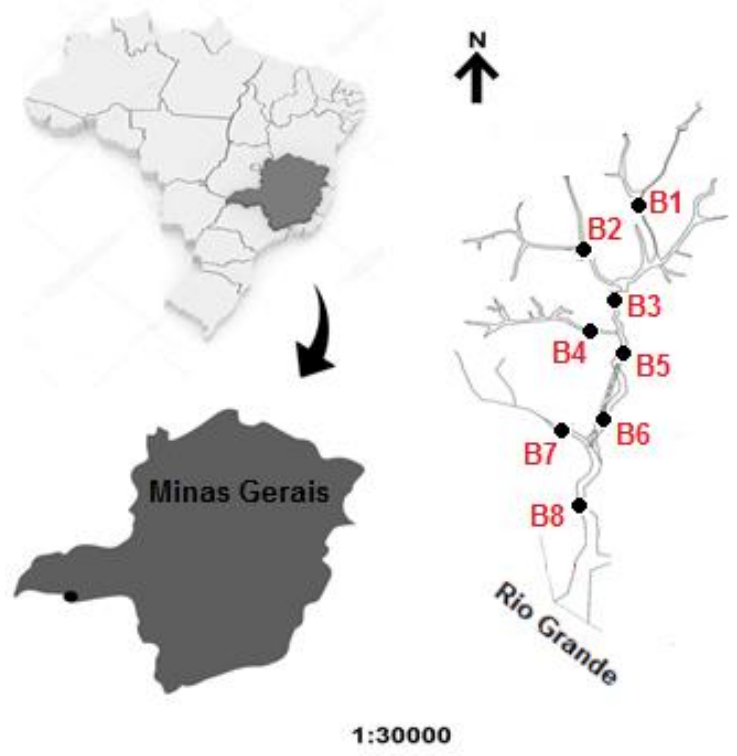

Figura 1. Localização da bacia hidrográfica do córrego Bebedouro no município de Frutal, Estado de Minas Gerais, Brasil, e os pontos de amostragens da ictiofauna.

Com o auxílio de uma sonda multiparâmetro foram mensurados in situ o $\mathrm{pH}$, o oxigênio dissolvido, a condutividade elétrica, os sólidos totais dissolvidos e a temperatura para cada ponto amostral. Amostras de água também foram obtidas para 
a determinação da alcalinidade total, clorofila$\alpha$, fósforo total, nitrogênio total, dureza, turbidez, coliformes totais e fecais. A determinação dessas variáveis foi feita em laboratório de acordo com o Standard Methods of Water and Wastewater (APHA et al., 2017). Além disso, foi aplicado o protocolo de Callisto et al. (2001) e obtida a vazão em cada ponto e período de coletas. A velocidade da água foi calculada com um flutuador em uma distância pré-determinada e a profundidade e a largura do riacho foram medidas com trena (precisão $1 \mathrm{~mm}$ ).

As coletas dos peixes foram realizadas em duas incursões, uma no período seco (setembro de 2012) e uma no período chuvoso (março de 2013) e para levantar o maior número de espécies possível, as capturas foram realizadas com diferentes petrechos de pesca para cada ponto de coleta: (1) Tarrafas rede de dois metros de altura e malha de 18 $\mathrm{mm}$, com um esforço de 10 lances por ponto de coleta; (2) Redes de espera - instaladas duas baterias contendo oito redes de diferentes malhas (de $3 \mathrm{~cm}$ a $12 \mathrm{~cm}$ entre nós opostos) às $18 \mathrm{hs}$ e retiradas às $6 \mathrm{hs}$ em cada ponto de coleta; (3) Puçás (70 cm x $60 \mathrm{~cm}$ ) com malha de $1,0 \mathrm{~mm}$ e esforço amostral de 30 minutos; (4) Pesca elétrica - realizada em trecho de 200 m por um período de 30 minutos utilizando-se uma combinação de eletrodos ligados a um gerador de corrente elétrica alternada $(220 \mathrm{v}$, $50-60 \mathrm{~Hz}, 3,4$ a 4,1 A, $1000 \mathrm{~W}$ ) e capturados com puçás.

Os peixes capturados foram separados em sacos plásticos identificados com data e local, anestesiados e fixados em formalina $10 \%$. Em laboratório foram conservados em álcool $70 \%$ e identificados com o auxílio de chaves de identificação e posteriormente confirmado pelo Prof. Dr. Osvaldo Takeshi Oyakawa do Setor de Ictiologia do Museu de Zoologia da USP. Os exemplares testemunhos foram depositados na coleção do museu da USP (MZUSP) sob os Vouchers de 115274 a 115296.
A partir dos dados amostrados foram obtidas a abundância, a riqueza, a diversidade de Shannon-Wiener, a dominância de Simpson e a uniformidade, por trecho do córrego e por ponto de coleta. Para cada trecho e para o total de espécies também foi calculada a constância de ocorrência (DAJOZ, 1978) e a partir do resultado obtido, cada espécie foi classificada em: constante $(\mathrm{C}>50 \%)$, acessória $(25 \% \leq \mathrm{A} \leq 50 \%)$ e acidental $(\mathrm{AC}<$ $25 \%)$.

As variáveis abióticas foram comparadas entre os períodos seco e chuvoso, por trecho no mesmo período (alto x médio, alto $\mathrm{x}$ foz e médio $\mathrm{x}$ foz) e por trecho entre os períodos (alto $\mathrm{x}$ alto, médio $\mathrm{x}$ médio e foz $\mathrm{x}$ foz), assim como o número de indivíduos capturados entre os trechos alto, médio e foz, por período e entre os trechos nos dois períodos. Essas análises foram realizadas com aplicação de ANOVA (one-way) e quando significativamente diferentes $(p<0,05)$ aplicou-se o teste de Dunnett, utilizando o software livre BioEstat 5.0. Para verificar se a abundância, diversidade e riqueza foram estatisticamente diferentes, utilizou-se ANOVA (one-way) no software R, com teste de normalidade dos resíduos (Shapiro Wilk) e homogeneidade das variâncias pelo teste de Levene. Quando atendido os requisitos e as amostras se confirmando significativamente diferentes $(p<0,05)$ aplicou-se o teste de Tukey e quando o modelo não atingiu os requisitos de normalidade e homogeneidade de variância, aplicou-se o teste de Kruskal-Wallis com comparações múltiplas.

Para a caracterização do ambiente, foi realizada uma análise de componentes principais (ACP) para todo o período. Essa análise foi realizada com as variáveis mensuradas da água e o protocolo de avaliação de Callisto et al., 2001, com 999 autoreamostragens (Bootstrap) através do 


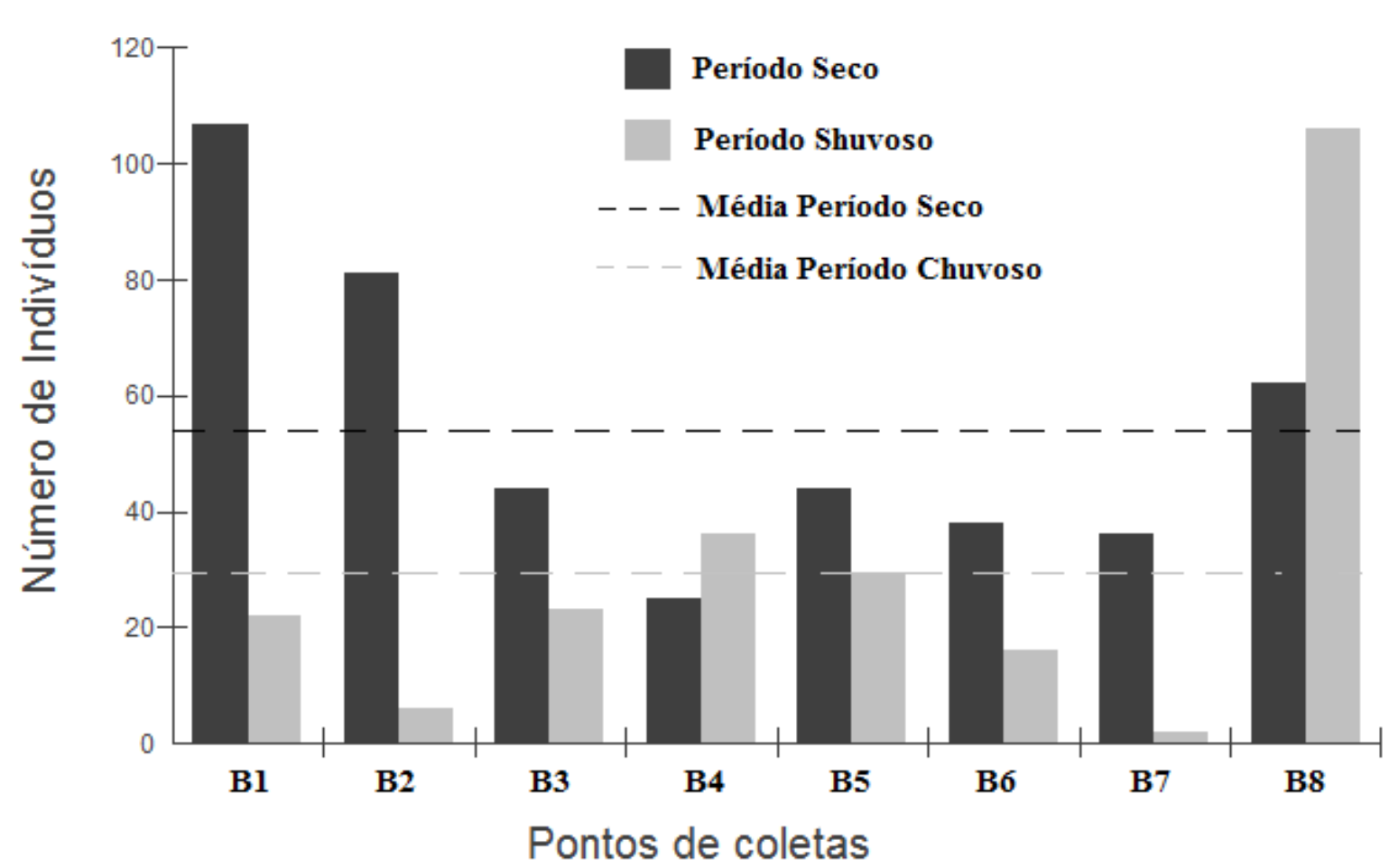

Figura 2. Variação espacial da abundância dos peixes nos diferentes pontos do córrego Bebedouro nos períodos seco e chuvoso.

programa estatístico PAST 3.20. Já para testar se as variáveis abióticas influenciaram a diversidade, a abundância e a riqueza de espécies foram realizadas análises de regressão linear múltipla através do programa estatístico BioEstat 5.0. Os resultados foram considerados significativos quando o valor de $p$ (coeficiente de regressão) foi menor do que 0,05 .

\section{Resultados}

Os pontos amostrados apresentaram uma acentuada hidrodinâmica com fundo rochoso, pedregoso ou arenoso, sendo alguns impactos verificados como a supressão da mata ripária, o assoreamento, o represamento nos trechos alto, médio e foz, além do lançamento de esgoto doméstico no trecho médio. $\mathrm{O} \mathrm{pH}$ da água manteve-se em torno da neutralidade com média total de $6,95( \pm 0,22)$. A condutividade foi mais elevada no período chuvoso com média de $61,75 \mathrm{mS} . \mathrm{cm}^{-1}( \pm$ $12,18)$, assim como os sólidos totais $(39,87 \pm$ 7,69 partes por milhão), a temperatura da água $\left(27,08 \pm 1,32{ }^{\circ} \mathrm{C}\right)$, a dureza $(47,49 \pm 5,41 \mathrm{mg}$ de $\mathrm{CaCo} 3 / \mathrm{L})$ e a clorofila- $\alpha(1,16 \pm 1,12$ $\mu \mathrm{g} / \mathrm{L})$. Às variáveis coliformes totais $(4840,75$ $\pm 8217,27$ cél/100 mL), coliformes fecais (4242,9 $( \pm 8195,63$ cél/100 mL), alcalinidade total $(32,02 \pm 2,87 \mathrm{mg}$ de $\mathrm{CaCO} / \mathrm{L})$, oxigênio dissolvido $(6,76 \pm 0,76 \mathrm{mg} / \mathrm{L})$ e vazão $(0,37 \pm$ $0,28)$ obtiveram maiores valores médios no período seco. (Tabela 1).

De acordo com aplicação do Protocolo de Avaliação de Callisto et al. (2001) entre os oito pontos avaliados nos dois períodos, dois pontos foram considerados impactados (B7 e B8), dois alterados (B1 e B2) e quatro (B3, B4, B5 e B6) foram avaliados como naturais. Contudo, considerando a média dos valores encontrados $(56,62 \pm 19,11)$ todos os trechos podem ser considerados alterados.

Diferenças estatísticas sazonais foram verificadas para as variáveis, condutividade ( $p$ $=0,0296)$, sólidos totais dissolvidos $(p=$ $0,0014)$, dureza total $(p=<0,0001)$, coliformes totais $(p=0,0193)$, vazão $(p=$ $0,0395)$, turbidez $(p=0,0368)$ e alcalinidade total $(p=<0,0001)$. As variáveis Protocolo de 
Avaliação de Callisto et al. (2001) ( $p=$ $0,8413)$, oxigênio dissolvido $(p=0,1218), \mathrm{pH}$ $(p=0,0973)$, temperatura $(p=0,6519)$, clorofila- $\alpha(p=0,3131)$ e coliformes fecais $(p$ $=0,9308$ ) não apresentaram diferenças significativas entre os períodos amostrados.

No período seco, entre os trechos alto e foz, foram verificadas diferenças significativas para as variáveis condutividade elétrica $(p=0,045 ; \mathrm{F}=11,03)$, sólidos totais dissolvidos $(p=0,04 ; \mathrm{F}=12,1)$, temperatura $(p=0,025 ; \mathrm{F}=16,96)$ e clorofila $\alpha(p=0,024$; $\mathrm{F}=17,61)$. Na comparação entre os trechos médio e foz, apenas a variável protocolo de Callisto ( $\mathrm{p}=0,002 ; \mathrm{F}=47,76)$ apresentou diferença e entre os trechos alto $\mathrm{x}$ médio não houve diferença significativa para nenhuma das variáveis. No período chuvoso, apenas a variável protocolo de Callisto foi estatisticamente diferente $(\mathrm{p}=0,002 ; \mathrm{F}=$ $43,36)$ entre os trechos médio e foz.

No total foram capturados 677 indivíduos pertencentes a 50 espécies, distribuídos em seis ordens e 17 famílias, sendo 239 indivíduos no período chuvoso e 438 no período seco. Destas espécies, cinco são exóticas, Apareiodon affinis (STEINDACHNER, 1879), Cichla kelberi (KULLANDER e FERREIRA, 2006), Plagioscion squamosissimus (HECKEL, 1840), Satanoperca pappaterra (HECKEL, 1840) e Tilapia rendalli (BOULENGER, 1897) e 45 são nativas. Dentre as espécies nativas, nenhuma apresentou status de avaliação quanto à ameaça de extinção (FISHBASE, 2017; IUCN, 2017). Hemigrammus sp. (GILL, 1858) foi a mais representativa com $13,29 \%(\mathrm{~N}=90)$ do total encontrado, seguida por Aspidoras fuscoguttatus (NIJSSEN \& ISBRÜCKER, 1976) $(\mathrm{N}=85 ; 12,55 \%)$, Astyanax scabripinnis (EIGENMANN, 1908) $(\mathrm{N}=56$; $8,27 \%$ ) e Planaltina britski (MENEZES et al., 2003) $(\mathrm{N}=46 ; 6,79 \%)$.

Durante o período chuvoso, no trecho alto, houve maior registro para Astyanax sp. com $33,33 \%(\mathrm{~N}=17)$, no trecho médio para Aspidoras fuscoguttatus, com $36,58 \%$ ( $\mathrm{N}=$
30) e na foz para Serrapinus heterodon (EIGENMANN, 1915) com 20,75\% ( $\mathrm{N}=22)$. Já no período seco, Hemigrammus sp. foi a espécie mais representada nos trechos alto e médio com $25,86 \%(\mathrm{~N}=60)$ e $20,98 \%(\mathrm{~N}=$ 30) respectivamente, enquanto Aspidoras fuscoguttatus foi a mais registrada, com $38,09 \%(\mathrm{~N}=24)$, na foz (Tabela 2).

Para a abundância das espécies nos diferentes pontos de amostragem, observou-se que a maioria dos pontos esteve abaixo da média geral. Os pontos B1 e B2 (período seco) e o ponto B8 (período chuvoso) foram os que apresentaram maiores abundâncias, respectivamente. Nos pontos B2 $(n=6), B 6(n$ $=16)$ e B7 $(n=2)$, no período chuvoso, foram registradas as menores abundâncias (Figura 2). Não foram verificadas diferenças significativas na abundância de espécies entre os períodos seco e chuvoso ( $p=0,1213)$.

Entre os trecho do córrego, também não foram verificadas diferenças significativas na abundância de espécies para o período chuvoso: alto x médio $(p=0,5164)$; alto $\mathrm{x}$ foz $(p=0,1585)$; médio $\mathrm{x}$ foz $(p=$ $0,6331)$; assim como no período seco: alto $\mathrm{x}$ médio ( $p=0,6075)$; alto $\mathrm{x}$ foz $(p=0,0767)$; médio $\mathrm{x}$ foz $(p=0,1523)$. Na comparação entre os mesmos trechos, entre os períodos, da mesma forma não foram encontradas diferenças significativas: alto $\mathrm{x}$ alto $(p=$ $0,0531)$; médio $\mathrm{x}$ médio $(p=0,3168)$; foz $\mathrm{x}$ foz $(p=0,6723)$.

A constância de ocorrência, para o total de espécies, evidenciou que nenhuma espécie foi classificada como constante (presente em mais de $50 \%$ das amostras), nove espécies foram enquadradas como acessórias (presentes entre $25 \%$ e $50 \%$ das amostras) e 41 como acidentais (presentes em menos de $25 \%$ das amostras). Para os trechos do córrego separadamente, foram encontradas apenas cinco espécies classificadas como constantes, sendo Geophagus brasiliensis no trecho alto, Aspidoras fuscoguttatus no trecho médio, Hypostomus sp. no trecho médio e na 
Tabela 1. Valores dos parâmetros físicos e químicos da água obtidos nos pontos de coletas nos períodos chuvoso e seco no córrego Bebedouro.

\begin{tabular}{|c|c|c|c|c|c|c|c|c|c|c|}
\hline \multicolumn{11}{|c|}{ CHUVOSO } \\
\hline PARÂMETRO & B01 & B02 & B03 & B04 & B05 & B06 & B07 & B08 & Média & D.P. \\
\hline $\begin{array}{l}\text { *P. A. Callisto et al. } \\
2001\end{array}$ & 41 & 63 & 80 & 77 & 68 & 47 & 34 & 35 & 55,62 & 17,46 \\
\hline Temperatura $\left({ }^{\circ} \mathrm{C}\right)$ & 26,08 & 25,97 & 27 & 27,91 & 26,62 & 26,6 & 26,29 & 30,23 & 27,09 & 1,32 \\
\hline $\mathrm{pH}$ & 6.7 & 6,89 & 6,86 & 7,22 & 6,82 & 6,74 & 6,45 & 7,17 & 6,86 & 0,24 \\
\hline $\begin{array}{l}\text { Condutividade } \\
\left(\mathrm{mS} . \mathrm{cm}^{-1}\right)\end{array}$ & 45 & 53 & 60 & 75 & 54 & 61 & 86 & 60 & 61,75 & 12,18 \\
\hline $\begin{array}{l}\text { Oxigênio Dissolvido } \\
\left(\mathrm{mg} . \mathrm{L}^{-1}\right)\end{array}$ & 5,49 & 5,5 & 6 & 7,63 & 4,7 & 6,75 & 4,08 & 6,16 & 5,79 & 1,05 \\
\hline $\begin{array}{l}\text { Dureza total }(\mathrm{mg} \text { de } \\
\mathrm{CaCo} 3 / \mathrm{L})\end{array}$ & 43,5 & 52,2 & 52,2 & 55,1 & 43,5 & 46,4 & 37,7 & 49,3 & 47,49 & 5,41 \\
\hline Clorofila- $\alpha(\mu \mathrm{g} / \mathrm{L})$ & 0,53 & 1,2 & 1,87 & 0,13 & 3,74 & 0,94 & 0,8 & 0,04 & 1,16 & 1,12 \\
\hline $\begin{array}{l}\text { Coliform. Totais } \\
\text { (cél/100 mL) }\end{array}$ & 20980 & 101120 & 101120 & 19130 & 17800 & 27230 & 19100 & 17600 & 40510 & 35108,81 \\
\hline $\begin{array}{l}\text { Coliform. Fecais } \\
\text { (cél/100 mL) }\end{array}$ & 410 & 16160 & 12960 & 410 & 630 & 520 & 100 & 100 & 3911.3 & 6202,29 \\
\hline Vazão m³/s & 0,626 & 0,695 & 3 & 0,385 & 3 & 3 & 0,437 & 0,38 & 1,42 & 1,19 \\
\hline Turbidez & 5,4 & 7,8 & 4,8 & 9,4 & 5 & 5,7 & 5,1 & 2,1 & 5,67 & 2,02 \\
\hline $\begin{array}{c}\text { *Alcal. total (mg de } \\
\text { CaCO3/L) }\end{array}$ & 12,38 & 14,63 & 15 & 12,75 & 17,25 & 18,75 & 19,13 & 15,75 & 15,7 & 2,37 \\
\hline *S.T.D. (PPM) & 29 & 34 & 39 & 48 & 35 & 40 & 55 & 39 & 39.87 & 7,69 \\
\hline \multicolumn{11}{|c|}{ SECO } \\
\hline PARÂMETRO & B01 & B02 & B03 & B04 & B05 & B06 & B07 & B08 & Média & D.P. \\
\hline $\begin{array}{l}\text { P. A. Callisto et al. } \\
2001\end{array}$ & 49 & 66 & 85 & 85 & 70 & 43 & 29 & 34 & 57,62 & 20,58 \\
\hline Temperatura $\left({ }^{\circ} \mathrm{C}\right)$ & 21,6 & 24,8 & 28,6 & 28,2 & 24,3 & 28,3 & 27,9 & 29 & 26,59 & 2,51 \\
\hline $\mathrm{pH}$ & 7,08 & 7,14 & 7 & 7,27 & 6,94 & 7,26 & 6,92 & 6,76 & 7,05 & 0,16 \\
\hline $\begin{array}{l}\text { Condutividade } \\
\left(\mathrm{mS} . \mathrm{cm}^{-1}\right)\end{array}$ & 32 & 34 & 29 & 42 & 86 & 37 & 41 & 42 & 42,87 & 16,91 \\
\hline $\begin{array}{l}\text { Oxigênio Dissolvido } \\
\left(\mathrm{mg} . \mathrm{L}^{-1}\right)\end{array}$ & 7,32 & 6,48 & 7,23 & 6,3 & 7,7 & 6,46 & 5,13 & 6,09 & 6,48 & 0,76 \\
\hline $\begin{array}{l}\text { Dureza total }(\mathrm{mg} \text { de } \\
\mathrm{CaCo} 3 / \mathrm{L})\end{array}$ & 21,71 & 25,05 & 23,38 & 23,38 & 30,06 & 21,71 & 25,05 & 25,05 & 24,42 & 2,49 \\
\hline Clorofila- $\alpha(\mu \mathrm{g} / \mathrm{L})$ & 0,94 & 0,94 & 0,67 & 1,74 & 0,13 & 0,13 & 0,27 & 0,53 & 0,67 & 0,51 \\
\hline $\begin{array}{l}\text { Coliform. Totais } \\
\text { (cél/100 mL) }\end{array}$ & 1011 & 1011 & 1011 & 1011 & 1011 & 26030 & 1011 & 6630 & 4840.8 & 8217,27 \\
\hline $\begin{array}{l}\text { Coliform. Fecais } \\
\text { (cél/100 mL) }\end{array}$ & 190 & 629 & 270 & 525 & 81 & 25150 & 168 & 6930 & 4242.9 & 8195,63 \\
\hline Vazão m³/s & 0,212 & 0,23 & 0,187 & 0,343 & 0,945 & 0,733 & 0,063 & 0,283 & 0,37 & 0,28 \\
\hline Turbidez & 4,86 & 6,65 & 6,55 & 7,85 & 14,13 & 7,42 & 18,37 & 19,91 & 10,71 & 5,5 \\
\hline $\begin{array}{l}\text { Alcal. total (mg de } \\
\text { CaCO3/L) }\end{array}$ & 29,59 & 28,06 & 29,59 & 36,99 & 32,15 & 33,93 & 34,95 & 30,87 & 32,02 & 2,87 \\
\hline S.T.D. (PPM) & 15 & 16 & 14 & 21 & 45 & 18 & 21 & 20 & 21,25 & 9,32 \\
\hline Profundidade média & 0,3 & 0,2 & 0,2 & 0,2 & 0,2 & 0,2 & 0,3 & 0,3 & 0,24 & 0,052 \\
\hline Largura média & 2 & 1,8 & 1,8 & 1,8 & 2,8 & 2,3 & 2 & 2 & 2,06 & 0,34 \\
\hline
\end{tabular}

*P. A. (Protocolo de Avaliação); Alcal. (Alcalinidade); S.T.D. (Sólidos Totais Dissolvidos); D.P. (Desvio Padrão). A profundidade e largura médias foram mensuradas apenas no período chuvoso. 
Tabela 2. Abundância total e relativa dos peixes capturados em todo o estudo e em cada trecho (nos dois períodos amostrados) do córrego Bebedouro.

\begin{tabular}{|c|c|c|c|c|c|c|c|c|c|c|}
\hline \multirow{2}{*}{ Ordem/Família } & \multirow{2}{*}{ Espécies } & \multirow{2}{*}{ Status } & \multirow{2}{*}{ Total } & \multirow{2}{*}{$\%$} & \multicolumn{3}{|c|}{ Chuvoso } & \multicolumn{3}{|c|}{ Seco } \\
\hline & & & & & Al & Me & Foz & Al & Me & Foz \\
\hline \multicolumn{11}{|c|}{ CHARACIFORMES } \\
\hline Anostomidae & Leporinus sp. & Nativa & 2 & 0.295 & 0 & 0 & 2 & 0 & 0 & 0 \\
\hline Characidae & Astyanax sp. (Baird \& Girard, 1854) & Nativa & 22 & 3.25 & 17 & 0 & 0 & 1 & 3 & 1 \\
\hline Characidae & Astyanax altiparanae (Garutti \& Britski, 2000) & Nativa & 1 & 0.148 & 0 & 0 & 1 & 0 & 0 & 0 \\
\hline Characidae & Astyanax fasciatus (Cuvier, 1819) & Nativa & 8 & 1.182 & 0 & 0 & 6 & 0 & 1 & 1 \\
\hline Characidae & Astyanax scabripinnis (Eigenmann, 1908) & Nativa & 56 & 8.272 & 0 & 0 & 2 & 52 & 1 & 1 \\
\hline Characidae & Bryconamericus sp. & Nativa & 22 & 3.25 & 1 & 19 & 0 & 0 & 0 & 2 \\
\hline Characidae & Bryconamericus stramineus (Eigenmann, 1908) & Nativa & 1 & 0.148 & 0 & 1 & 0 & 0 & 0 & 0 \\
\hline Characidae & Hemigrammus sp. (Gill, 1858) & Nativa & 90 & 13.29 & 0 & 0 & 0 & 60 & 30 & 0 \\
\hline Characidae & Hemigrammus marginatus (Ellis, 1911) & Nativa & 13 & 1.92 & 0 & 0 & 13 & 0 & 0 & 0 \\
\hline Characidae & Hyphessobrycon eques (Steindachner, 1882) & Nativa & 34 & 5.022 & 0 & 1 & 10 & 0 & 23 & 0 \\
\hline Characidae & Hyphessobrycon anisitsi (Eigenmann, 1907) & Nativa & 2 & 0.295 & 2 & 0 & 0 & 0 & 0 & 0 \\
\hline Characidae & Hyphessobrycon bifasciatus (Ellis, 1911) & Nativa & 7 & 1.034 & 0 & 0 & 0 & 7 & 0 & 0 \\
\hline Characidae & Moenkhausia sp. & Nativa & 2 & 0.295 & 0 & 0 & 0 & 0 & 2 & 0 \\
\hline Characidae & Moenkhausia intermedia (Eigenmann, 1908) & Nativa & 4 & 0.591 & 0 & 0 & 4 & 0 & 0 & 0 \\
\hline Characidae & Oligosarcus sp. & Nativa & 1 & 0.148 & 0 & 0 & 0 & 0 & 0 & 1 \\
\hline Characidae & Oligosarcus pintoi (Campos, 1945) & Nativa & 4 & 0.591 & 0 & 0 & 4 & 0 & 0 & 0 \\
\hline Characidae & Piabina argentea (Reinhardt, 1867) & Nativa & 16 & 2.363 & 14 & 0 & 0 & 0 & 2 & 0 \\
\hline Characidae & Planaltina britskii (Menezes et al., 2003) & Nativa & 46 & 6.795 & 0 & 0 & 0 & 45 & 0 & 1 \\
\hline Characidae & Serrapinus sp. & Nativa & 1 & 0.148 & 0 & 0 & 0 & 0 & 1 & 0 \\
\hline Characidae & Serrapinnus notomelas (Eigenmann, 1915) & Nativa & 37 & 5.465 & 0 & 1 & 12 & 17 & 7 & 0 \\
\hline Characidae & Serrapinus heterodon (Eigenmann, 1915) & Nativa & 22 & 3.25 & 0 & 0 & 22 & 0 & 0 & 0 \\
\hline Crenuchidae & Characidium $\mathrm{sp}$ & Nativa & 17 & 2.511 & 0 & 2 & 0 & 14 & 1 & 0 \\
\hline Crenuchidae & Characidium zebra (Eigenmann, 1909) & Nativa & 7 & 1.034 & 3 & 4 & 0 & 0 & 0 & 0 \\
\hline Erythrinidae & Hoplias malabaricus (Bloch, 1794) & Nativa & 2 & 0.295 & 0 & 1 & 1 & 0 & 0 & 0 \\
\hline Lebiasinidae & $\begin{array}{l}\text { Pyrrhulina australis (Eigenmann \& Kennedy, } \\
\text { 1903) }\end{array}$ & Nativa & 1 & 0.148 & 0 & 0 & 0 & 0 & 1 & 0 \\
\hline Parodontidae & Apareiodon affinis (Steindachner, 1879) & Exótica & 1 & 0.148 & 1 & 0 & 0 & 0 & 0 & 0 \\
\hline Serrasalmidae & Metynis sp. & Nativa & 3 & 0.443 & 0 & 0 & 1 & 0 & 0 & 2 \\
\hline \multicolumn{11}{|l|}{ SILURIFORMES } \\
\hline Callichthyidae & $\begin{array}{l}\text { Aspidoras fuscoguttatus (Nijssen \& Isbrücker, } \\
\text { 1976) }\end{array}$ & Nativa & 85 & 12.56 & 1 & 30 & 0 & 11 & 19 & 24 \\
\hline Heptapteridae & $\begin{array}{l}\text { Cetopsorhamdia iheringi (Schubart \& Gomes, } \\
\text { 1959) }\end{array}$ & Nativa & 1 & 0.148 & 1 & 0 & 0 & 0 & 0 & 0 \\
\hline Heptapteridae & Imparfinis schubarti (Gomes, 1956) & Nativa & 3 & 0.443 & 0 & 3 & 0 & 0 & 0 & 0 \\
\hline Heptapteridae & Imparfinis mirini (Haseman, 1911) & Nativa & 1 & 0.148 & 0 & 1 & 0 & 0 & 0 & 0 \\
\hline Heptapteridae & Imparfinis sp. & Nativa & 2 & 0.295 & 0 & 2 & 0 & 0 & 0 & 0 \\
\hline Heptapteridae & Phenacorhamdia sp. & Nativa & 3 & 0.443 & 0 & 0 & 0 & 0 & 3 & 0 \\
\hline Heptapteridae & Phenacorhamdia. tenebrosa (Schubart, 1964) & Nativa & 3 & 0.443 & 2 & 1 & 0 & 0 & 0 & 0 \\
\hline Loricariidae & Hisonotus sp. & Nativa & 24 & 3.545 & 0 & 0 & 0 & 5 & 19 & 0 \\
\hline Loricariidae & Hypostomus sp. & Nativa & 40 & 5.908 & 2 & 2 & 0 & 13 & 18 & 5 \\
\hline Loricariidae & Hypostomus ancistroides (Ihering, 1911) & Nativa & 15 & 2.216 & 1 & 14 & 0 & 0 & 0 & 0 \\
\hline Loricariidae & Hypostomus nigromaculatos (Schubart, 1967) & Nativa & 4 & 0.591 & 4 & 0 & 0 & 0 & 0 & 0 \\
\hline Pimelodidae & Pimelodus maculatus (La Cepède, 1803) & Nativa & 3 & 0.443 & 0 & 0 & 3 & 0 & 0 & 0 \\
\hline \multicolumn{11}{|c|}{ GYMNOTIFORMES } \\
\hline Sternopygidae & Eigenmannia virescens (Valenciennes, 1847) & Nativa & 2 & 0.295 & 0 & 0 & 0 & 2 & 0 & 0 \\
\hline Gymnotidae & $\begin{array}{l}\text { Gymnotus sylvius (Albert \& Fernandes-Matioli, } \\
\text { 1999) }\end{array}$ & Nativa & 9 & 1.329 & 0 & 0 & 0 & 1 & 8 & 0 \\
\hline \multicolumn{11}{|c|}{ SYNBRANCHIFORMES } \\
\hline Synbranchidae & Symbrancus mormoratus Bloch, 1795 (Nat) & Nativa & 1 & 0.148 & 0 & 0 & 0 & 1 & 0 & 0 \\
\hline \multicolumn{11}{|l|}{ PERCIFORMES } \\
\hline Cichlidae & Cichlasoma paranaense (Kullander, 1983) & Nativa & 2 & 0.295 & 0 & 0 & 1 & 0 & 1 & 0 \\
\hline Cichlidae & Cichla kelberi (Kullander \& Ferreira, 2006) & Exótica & 17 & 2.511 & 0 & 0 & 0 & 0 & 0 & 17 \\
\hline Cichlidae & Geophagus brasiliensis (Quoy \& Gaimard, 1824) & Nativa & 10 & 1.477 & 2 & 0 & 2 & 3 & 3 & 0 \\
\hline Cichlidae & Satanoperca pappaterra (Heckel, 1840) & Exótica & 4 & 0.591 & 0 & 0 & 4 & 0 & 0 & 0 \\
\hline Cichlidae & Tilapia rendalli (Boulenger, 1897) (Exo) & Exótica & 1 & 0.148 & 0 & 0 & 0 & 0 & 0 & 1 \\
\hline Sciaenidae & $\begin{array}{l}\text { Plagioscion squamosissimus (Heckel, 1840) } \\
\text { (Exo) }\end{array}$ & Exótica & 6 & 0.886 & 0 & 0 & 3 & 0 & 0 & 3 \\
\hline \multicolumn{11}{|c|}{ CYPRINODONTIFORMES } \\
\hline Poeciliidae & Phaloceros sp. & Nativa & 4 & 0.591 & 0 & 0 & 0 & 0 & 0 & 4 \\
\hline Poeciliidae & Phalloceros harpagos & Nativa & 15 & 2.216 & 0 & 0 & 15 & 0 & 0 & 0 \\
\hline & TOTAL & & 677 & 100 & 51 & 82 & 106 & 232 & 143 & 63 \\
\hline
\end{tabular}

*Al = Trecho alto; $\mathrm{Me}=$ Trecho médio. 
Tabela 3. Constância de ocorrência das espécies de peixes no córrego Bebedouro, Frutal, Minas Gerais, para o total de espécies e para os trechos alto, médio e foz.

\begin{tabular}{|c|c|c|c|c|c|c|c|c|}
\hline Espécie & Total & $\%$ & Alto & $\%$ & Médio & $\%$ & Foz & $\%$ \\
\hline Apareiodon affinis & $\mathrm{AC}$ & 6,25 & ---- & 0 & $\mathrm{AC}$ & 25 & ---- & 0 \\
\hline Aspidoras fuscoguttatus & A & 37,5 & $\mathrm{AC}$ & 25 & $\mathrm{C}$ & 100 & $\mathrm{AC}$ & 25 \\
\hline Astyanax altiparanae & $\mathrm{AC}$ & 6,25 & ---- & 0 & ---- & 0 & $\mathrm{AC}$ & 25 \\
\hline Astyanax fasciatus & $\mathrm{AC}$ & 18,75 & ---- & 0 & $\mathrm{AC}$ & 25 & A & 50 \\
\hline Astyanax scabripinnis & A & 31,25 & A & 50 & $\mathrm{AC}$ & 25 & A & 50 \\
\hline Astyanax sp. & $\mathrm{AC}$ & 18,75 & A & 50 & ---- & 0 & $\mathrm{AC}$ & 25 \\
\hline Briconamericus stramineus & $\mathrm{AC}$ & 6,25 & ---- & 0 & ---- & 0 & $\mathrm{AC}$ & 25 \\
\hline Briconamericus sp. & $\mathrm{AC}$ & 18,75 & $\mathrm{AC}$ & 25 & $\mathrm{AC}$ & 25 & $\mathrm{AC}$ & 25 \\
\hline Cetopsorhamdia iheringi & $\mathrm{AC}$ & 6,25 & $\mathrm{AC}$ & 25 & ---- & 0 & ---- & 0 \\
\hline Characidium sp. & $\mathrm{AC}$ & 18,75 & $\mathrm{AC}$ & 25 & $\mathrm{AC}$ & 25 & $\mathrm{AC}$ & 25 \\
\hline Characidium zebra & A & 25 & $\mathrm{AC}$ & 25 & A & 50 & $\mathrm{AC}$ & 25 \\
\hline Cichlasoma paranaenses & $\mathrm{AC}$ & 12,5 & ---- & 0 & ---- & 0 & A & 50 \\
\hline Cicla monoculus & $\mathrm{AC}$ & 6,25 & ---- & 0 & ---- & 0 & $\mathrm{AC}$ & 25 \\
\hline Eigenmannia virensis & $\mathrm{AC}$ & 6,25 & ---- & 0 & $\mathrm{AC}$ & 25 & ---- & 0 \\
\hline Geophagus brasiliensis & A & 37,5 & $\mathrm{C}$ & 75 & $\mathrm{AC}$ & 25 & $\mathrm{AC}$ & 25 \\
\hline Gymnotus sylvius & A & 25 & $\mathrm{AC}$ & 25 & A & 50 & $\mathrm{AC}$ & 25 \\
\hline Hemigrammus marginatus & $\mathrm{AC}$ & 6,25 & ---- & 0 & ---- & 0 & $\mathrm{AC}$ & 25 \\
\hline Hemigrammus sp. & $\mathrm{AC}$ & 18,75 & A & 50 & $\mathrm{AC}$ & 25 & ---- & 0 \\
\hline Hisonotus insperatus & A & 31,25 & A & 50 & $\mathrm{AC}$ & 25 & A & 50 \\
\hline Hoplias malabaricus & $\mathrm{AC}$ & 12,5 & ---- & 0 & ---- & 0 & A & 50 \\
\hline Hyphessobricon anisitsi & $\mathrm{AC}$ & 12,5 & $\mathrm{AC}$ & 25 & $\mathrm{AC}$ & 25 & ---- & 0 \\
\hline Hyphessobricon bifasciat & $\mathrm{AC}$ & 12,5 & A & 50 & ---- & 0 & ---- & 0 \\
\hline Hyphessobrycon eques & $\mathrm{AC}$ & 18,75 & ---- & 0 & ---- & 0 & $\mathrm{C}$ & 75 \\
\hline Hypostomus ancistroides & A & 25 & ---- & 0 & A & 50 & A & 50 \\
\hline Hypostomus nigromaculattus & $\mathrm{AC}$ & 12,5 & $\mathrm{AC}$ & 25 & $\mathrm{AC}$ & 25 & ---- & 0 \\
\hline Hypostomus sp. & A & 50 & $\mathrm{AC}$ & 25 & $\mathrm{C}$ & 100 & $\mathrm{C}$ & 75 \\
\hline Imparfinis schubarti & $\mathrm{AC}$ & 6,25 & ---- & 0 & ---- & 0 & $\mathrm{AC}$ & 25 \\
\hline Imparfinis mirini & $\mathrm{AC}$ & 6,25 & ---- & 0 & ---- & 0 & $\mathrm{AC}$ & 25 \\
\hline Imparfinis sp. & $\mathrm{AC}$ & 6,25 & ---- & 0 & ---- & 0 & $\mathrm{AC}$ & 25 \\
\hline Leporinus sp. & $\mathrm{AC}$ & 6,25 & ---- & 0 & ---- & 0 & $\mathrm{AC}$ & 25 \\
\hline Metynis sp. & $\mathrm{AC}$ & 12,5 & ---- & 0 & ---- & 0 & A & 50 \\
\hline Moenkhausia intermedia & $\mathrm{AC}$ & 6,25 & ---- & 0 & ---- & 0 & $\mathrm{AC}$ & 25 \\
\hline Moenkhausia sp. & $\mathrm{AC}$ & 6,25 & ---- & 0 & ---- & 0 & $\mathrm{AC}$ & 25 \\
\hline Oligosarcus sp. & $\mathrm{AC}$ & 6,25 & ---- & 0 & ---- & 0 & $\mathrm{AC}$ & 25 \\
\hline Oligosarcus pintoi & $\mathrm{AC}$ & 6,25 & ---- & 0 & ---- & 0 & $\mathrm{AC}$ & 25 \\
\hline Phaloceros sp. & $\mathrm{AC}$ & 6,25 & ---- & 0 & ---- & 0 & $\mathrm{AC}$ & 25 \\
\hline Phaloceros harpagos & $\mathrm{AC}$ & 6,25 & ---- & 0 & ---- & 0 & $\mathrm{AC}$ & 25 \\
\hline Phenacorhamdia sp. & $\mathrm{AC}$ & 6,25 & ---- & 0 & ---- & 0 & $\mathrm{AC}$ & 25 \\
\hline Phenacorhamdia tenebrosa & $\mathrm{AC}$ & 12,5 & $\mathrm{AC}$ & 25 & $\mathrm{AC}$ & 25 & ---- & 0 \\
\hline Piabina argenta & $\mathrm{AC}$ & 12,5 & ---- & 0 & $\mathrm{AC}$ & 25 & $\mathrm{AC}$ & 25 \\
\hline Pimelodus maculatus & $\mathrm{AC}$ & 6,25 & ---- & 0 & ---- & 0 & $\mathrm{AC}$ & 25 \\
\hline Plagioscion squamosissimus & $\mathrm{AC}$ & 12,5 & ---- & 0 & ---- & 0 & A & 50 \\
\hline Planaltina britski & $\mathrm{AC}$ & 18,75 & $\mathrm{AC}$ & 25 & $\mathrm{AC}$ & 25 & $\mathrm{AC}$ & 25 \\
\hline Pyrrhulina australis & $\mathrm{AC}$ & 6,25 & ---- & 0 & ---- & 0 & $\mathrm{AC}$ & 25 \\
\hline Satanoperca pappaterra & $\mathrm{AC}$ & 6,25 & ---- & 0 & ---- & 0 & $\mathrm{AC}$ & 25 \\
\hline Serrapinnus notomelas & A & 25 & ---- & 0 & $\mathrm{AC}$ & 25 & $\mathrm{C}$ & 75 \\
\hline Serrapinus heterodon & $\mathrm{AC}$ & 6,25 & ---- & 0 & ---- & 0 & $\mathrm{AC}$ & 25 \\
\hline Serrapinus sp. & $\mathrm{AC}$ & 6,25 & ---- & 0 & ---- & 0 & $\mathrm{AC}$ & 25 \\
\hline Symbrancus mormoratus & $\mathrm{AC}$ & 6,25 & $\mathrm{AC}$ & 25 & ---- & 0 & ---- & 0 \\
\hline Tilapia rendalli & $\mathrm{AC}$ & 6,25 & ---- & 0 & ---- & 0 & $\mathrm{AC}$ & 25 \\
\hline
\end{tabular}

*C - Constante: mais de 50\%; A - Acessória: de 25 a 50\%; AC - Acidentais: até 25\%. 
foz e Hyphessobrycon eques e Serrapinnus notomelas na foz (Tabela 3 ).

Comparando-se os trechos do córrego, foi verificado um total de 13 (chuvoso) e 14 (seco) espécies no trecho alto, 14 (chuvoso) e 18 (seco) no trecho médio e 18 (chuvoso) e 13 (seco) na foz, sendo os pontos B4 e B7 ( $\mathrm{n}=2$; chuvoso) os mais pobres em espécies e o ponto e B8 ( $\mathrm{n}=18$; chuvoso) com maior riqueza.

A diversidade de espécies foi maior no ponto B4 (0,4506 - período chuvoso) e considerando os trechos, foi maior na foz $(2,466$ - período chuvoso). A maior uniformidade foi no ponto B7 (1,0 - período chuvoso), sendo maior na foz $(0,8531$ período chuvoso) entre os trechos. Quanto à dominância, o maior valor foi no ponto B4 $(0,7222$ - período chuvoso) (Tabela 4). Não foram verificadas diferenças significativas, para essas variáveis, quando comparado os pontos, os trechos e as épocas do ano.

$\mathrm{Na}$ comparação entre a riqueza de espécies com as variáveis abióticas apenas a condutividade elétrica, os sólidos totais dissolvidos e a temperatura influenciam a riqueza de espécies no córrego bebedouro. Já para a comparação das relações entre abundância de espécies x variáveis abióticas e diversidade de espécies $\mathrm{x}$ variáveis abióticas, nenhuma das variáveis apresentou-se como significativa (tabela 5).

A caracterização do ambiente, através das variáveis abióticas da água, mostrou que no período seco os pontos B2, B3, B4 e B6 estiveram relacionados positivamente com as variáveis oxigênio dissolvido e $\mathrm{pH}$ da água, enquanto os pontos B1, B7 e B8 apresentaram relação negativa para as variáveis alcalinidade total, turbidez e profundidade. As variáveis largura e temperatura da água mostraram relação positiva apenas com o ponto B5. No período chuvoso, os pontos B2, B3, B4 e B5 se correlacionaram positivamente com as variáveis dureza, vazão e protocolo de Callisto et al. (2001) e clorofila- $\alpha$, além de terem apresentados os maiores valores para coliformes totais e coliformes fecais. Já os
Tabela 4. Riqueza (S), Diversidade de ShannonWiener (H'), Dominância de Simpson (D) e Uniformidade (E) da comunidade de peixes, entre os pontos de coletas e entre os trechos do córrego Bebedouro, nos períodos chuvoso e seco.

\begin{tabular}{|c|c|c|c|c|c|}
\hline \multicolumn{2}{|c|}{ Pontos de Coletas } & $\mathbf{S}$ & $\mathbf{H}^{\prime}$ & D & $\mathbf{E}$ \\
\hline \multicolumn{2}{|l|}{ B1 Seco } & 7 & 12,920 & 0,324 & 0,6639 \\
\hline \multicolumn{2}{|c|}{ B1 Chuvoso } & 4 & 0,7757 & 0,6157 & 0,5596 \\
\hline \multicolumn{2}{|l|}{ B2 Seco } & 10 & 15,230 & 0,3105 & 0,6616 \\
\hline \multicolumn{2}{|c|}{ B2 Chuvoso } & 4 & 13,300 & 0,2778 & 0,9591 \\
\hline \multicolumn{2}{|l|}{ B3 Seco } & 6 & 15,420 & 0,251 & 0,8607 \\
\hline \multicolumn{2}{|c|}{ B3 Chuvoso } & 8 & 14,090 & 0,3951 & 0,6774 \\
\hline \multicolumn{2}{|l|}{ B4 Seco } & 3 & 0,6592 & 0,6192 & 0,6 \\
\hline \multicolumn{2}{|c|}{ B4 Chuvoso } & 2 & 0,4506 & 0,7222 & 0,65 \\
\hline \multicolumn{2}{|l|}{ B5 Seco } & 7 & 10,950 & 0,4938 & 0,5626 \\
\hline \multicolumn{2}{|c|}{ B5 Chuvoso } & 4 & 0,9207 & 0,4935 & 0,6641 \\
\hline \multicolumn{2}{|c|}{ B6 Seco } & 6 & 13,990 & 0,3241 & 0,7805 \\
\hline \multicolumn{2}{|c|}{ B6 Chuvoso } & 10 & 22,200 & 0,1172 & 0,9641 \\
\hline \multicolumn{2}{|l|}{ B7 Seco } & 7 & 11,630 & 0,4522 & 0,5979 \\
\hline \multicolumn{2}{|c|}{ B7 Chuvoso } & 2 & 0,6931 & 0,5 & 10,000 \\
\hline \multicolumn{2}{|l|}{ B8 Seco } & 12 & 18,030 & 0,2414 & 0,7256 \\
\hline \multicolumn{2}{|c|}{ B8 Chuvoso } & 18 & 24,660 & 0,1194 & 0,8531 \\
\hline Trecho & Período & $\mathbf{S}$ & $\mathbf{H}^{\prime}$ & D & $\mathbf{E}$ \\
\hline \multirow{2}{*}{ Alto } & Chuvoso & 13 & 1,981 & 0,2042 & 0,7723 \\
\hline & Seco & 14 & 2,026 & 0,1708 & 0,7677 \\
\hline \multirow{2}{*}{ Médio } & Chuvoso & 14 & 1,871 & 0,2231 & 0,709 \\
\hline & Seco & 18 & 2,299 & 0,1286 & 0,7953 \\
\hline \multirow{2}{*}{ Baixo } & Chuvoso & 18 & 2,466 & 0,1104 & 0,8531 \\
\hline & Seco & 13 & 1,856 & 0,2341 & 0,7235 \\
\hline
\end{tabular}

pontos B1, B6, B7 e B8 apresentaram correlação positiva para condutividade elétrica e sólidos totais dissolvidos (Figura 3). Foi verificado que apenas a condutividade elétrica, sólidos totais dissolvidos e a temperatura influenciam a riqueza de espécies. Para abundância e diversidade de espécies, as variáveis abióticas, não exercem influência (tabela 5).

\section{DiSCUSSÃO}

Os resultados encontrados nesse estudo demostraram que o córrego Bebedouro apresentou trechos com características naturais, alteradas e impactadas. Isso ocorreu em função das perturbações as quais os trechos alto, com represamentos e processos erosivos, médio, com lançamento de esgoto e 


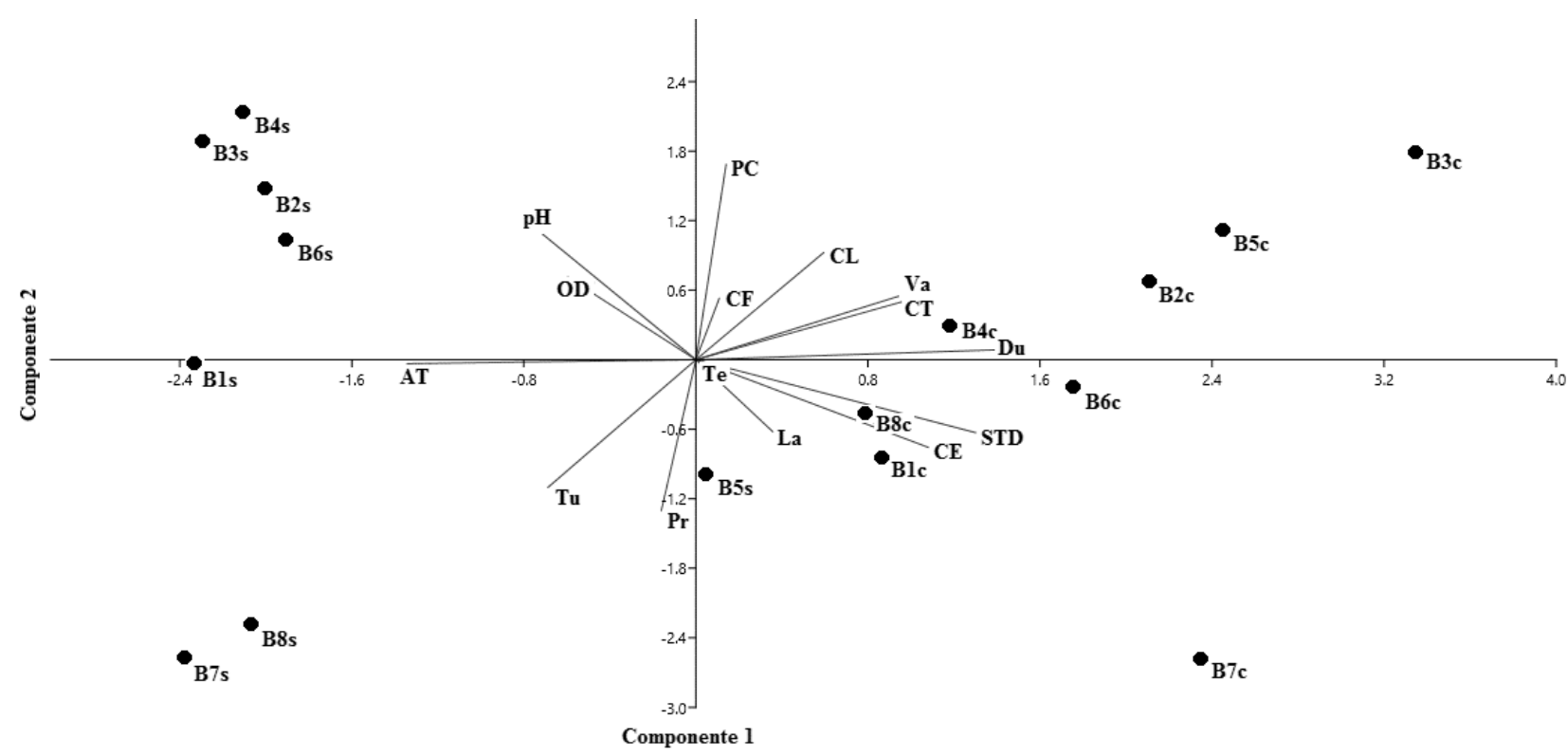

Figura 3. Análise dos Componentes Principais dos fatores abióticos da água. Eixo 1: 29,26 \% da variabilidade total dos dados; Eixo 2: 16,41\% da variabilidade total dos dados.

*pH - Potencial hidrogeniônico; Co - Condutividade elétrica; OD - Oxigênio dissolvido; T Temperatura da água; STD - Sólidos totais dissolvidos; V - Vazão; CT - Coliformes totais; CF Coliformes fecais; PC - Protocolo de avaliação de Callisto; Tu - Turbidez; Du - Dureza da água; $\mathrm{Cl}$ - Clorofila- $\alpha$; AT - Alcalinidade total; Pr - Profundidade; La - Largura.

processos erosivos e foz, com represamento e lançamento de esgoto, são submetidos. A pouca cobertura vegetal e o solo arenoso, em alguns locais, também podem ter sido determinantes no processo de assoreamento e os altos valores de sólidos totais dissolvidos registrados explicam esta situação. Contudo, as diferenças sazonais verificadas para alguns parâmetros ambientais, como a condutividade, sólidos totais dissolvidos, dureza, coliformes totais, vazão, turbidez e alcalinidade total, são esperadas, pois, a sazonalidade pode ter influência sobre essas variáveis devido ao aumento do volume de água na época chuvosa e diminuição na época seca.

A riqueza de espécies encontrada nesse estudo corrobora com Matthews (2012) que afirma que a maioria dos ambientes aquáticos dulcícolas, em todo o mundo, possuem entre 20 espécies e 100 espécies. Contudo, o número de espécies observadas no córrego Bebedouro foi alto quando comparado a outros estudos em ecossistemas tropicais e subtropicais no Sudeste do Brasil (MARQUES et al., 2013; AMORIM et al., 2013; SANTANA et al., 2016; AZEVEDOSANTOS et al., 2019). Também foi observado predomínio de Characiformes e Siluriformes, o que é esperado para rios sul-americanos (OYAKAWA e MENEZES, 2011), assim como foi verificado maior número de espécies pertencentes às famílias Characidae, Pimelodidae e Loricariidae, refletindo o padrão encontrado nas águas continentais brasileiras (SMITH et al., 2007; ESGUÍCERO e ARCIFA, 2011). Characidae foi predominante nas amostragens e segundo Buckup (1999), essa família constitui o principal grupo encontrado em riachos, tendo destaque os lambaris do gênero Astyanax com A. scabripinnis sendo a espécie mais abundantes em trechos d'água de baixa ordem 
(BENNEMANN et al., 2005), como verificado pelo presente estudo.

A maioria das espécies foi considerada acidental, como relatado por MATTHEWS (2012) que sugere que entre as comunidades ícticas ocorrem poucas espécies abundantes e muitas espécies representadas por poucos indivíduos. Entre os períodos, a variação da constância de espécies pode ser explicada devido a ocorrência de espécies mais comuns seja no período seco ou no chuvoso. Como a maioria das espécies são de pequeno porte, ou seja, não realizam grandes deslocamentos, podem estar restringindo suas distribuições à micro-habitat específicos, tornando as populações isoladas (CASTRO, 1999).

Os barramentos naturais, formados por trechos encachoeirados e/ou troncos de árvores caídos ao longo do córrego, contribuem para os hábitos mais residentes dessas espécies, assim como sugerido por Apone et al. (2008). Pringle et al. (1988) relatam que a biota aquática em ambientes lóticos pode responder a variações nas características de manchas do ambiente (i.e. mosaicos e trechos lênticos) ao longo das bacias de drenagem, sendo poucas espécies consideradas constantes. No presente estudo a foz do córrego obteve maior quantidade de espécies constantes, assim como observado por Pavanelli e Caramaschi (2003) em um rio na bacia do alto rio Paraná.

Diferenças sazonais não foram evidenciadas em relação à abundância, à riqueza, a diversidade, a dominância e a uniformidade das espécies quando comparado os trechos (alto, médio e foz) e entre os períodos (seco e chuvoso) nos mesmos trechos. De acordo Santos e Caramaschi (2011), a comunidade de peixes pode ser afetada por mudanças sazonais, devido à expansão do ambiente aquático da época seca para a chuvosa e Takahashi et al. (2013) afirmam que em áreas neotropicais, durante as chuvas, criam-se mais habitats para as espécies. Apesar disso, no presente estudo não foram verificadas diferenças em função da sazonalidade, podendo ser explicado pela

Tabela 5. Análises de regressões lineares múltiplas entre os preditores riqueza, diversidade e abundância e as variáveis dos locais estudados. A variável foi considerada como influente sobre os preditores quando $\mathrm{p}<0,05$. *P. A. = Protocolo de Avaliação; Alcal = Alcalinidade; S.T.D. = Sólidos Totais Dissolvidos.

\begin{tabular}{cccc}
\hline \multirow{2}{*}{ Variável } & \multicolumn{3}{c}{ Coeficiente de Regressão $(\boldsymbol{p})$} \\
\cline { 2 - 4 } & Riqueza & Diversidade & Abundância \\
\hline P. A. Callisto et al. 2001 & 0,5309 & 0,9435 & 0,582 \\
Temperatura $\left({ }^{\circ} \mathrm{C}\right)$ & $\mathbf{0 , 0 0 0 1}$ & 0,4207 & 0,4048 \\
pH & 0,1002 & 0,6912 & 0,929 \\
Condutividade $\left(\mathrm{mS} . \mathrm{cm}^{-1}\right)$ & $\mathbf{0 , 0 0 0 1}$ & 0,6301 & 0,2746 \\
Oxigênio Dissolvido $\left({\left.\mathrm{mg} . \mathrm{L}^{-1}\right)}\right)$ & 0,2304 & 0,9647 & 0,9419 \\
Dureza Total (mg de CaCO3/L) & 0,7431 & 0,8539 & 0,7059 \\
Clorofila- $\alpha(\mathrm{mg} . \mathrm{L})$ & 0,5909 & 0,5229 & 0,7625 \\
Coliformes Totais cél/100 mL) & 0,6985 & 0,5959 & 0,9949 \\
Coliformes Fecais cél/100 mL) & 0,8976 & 0,692 & 0,7603 \\
Vazão (m $3 / \mathrm{s})$ & 0,6549 & 0,578 & 0,9038 \\
Turbidez & 0,7873 & 0,7923 & 0,8602 \\
Alcal. Total (mg de CaCO3/L) & 0,5218 & 0,7496 & 0,1508 \\
S.T.D. (PPM) & $\mathbf{0 , 0 0 0 1}$ & 0,5947 & 0,2695 \\
Profundidade (Metros) & 0,4292 & 0,9279 & 0,2161 \\
Largura (Metros) & 0,7271 & 0,9952 & 0,5083 \\
\hline
\end{tabular}


ocorrência de uma intensa estiagem no ano de 2012 na região (ANA, 2017) que pode ter influenciado a hidrologia do córrego. Deve ser ressaltado que a abundância de espécies também é influenciada por mudanças ambientais imprevisíveis que podem alterar as populações como as modificações antropogênicas (OKADA et al., 2003; TAKAHASHI et al., 2013), sendo importantes causadoras de modificações na estrutura das comunidades (HIGGINS, 2009).

Os índices de diversidades, apresentados para os dois períodos mostraram um efeito inverso na foz do córrego Bebedouro, no qual o período seco obteve menor diversidade em relação ao período chuvoso. Essa inversão ocorreu pela destacada participação dos siluriformes e perciformes, que representaram o maior número de indivíduos capturados no período seco. Nos trechos alto e médio, ocorreram o esperado, pois naturalmente o período com maior temperatura apresenta uma maior atividade da comunidade íctica, devido ao alto metabolismo das espécies, abundância de alimentos trazidos pelas chuvas e pela época de reprodução (PIANA et al., 2006). Na foz, o aumento da diversidade ocorreu principalmente em função da possibilidade de colonização de novos micro-habitat disponíveis após a elevação do nível da água no córrego no período chuvoso e a fenômenos hidrológicos com características distintas no local. Enquanto na nascente o aumento do volume de água se deu, na maioria das vezes, em forma de picos agudos, com grande intensidade do volume e em curto espaço de tempo, possibilitando assim o estabelecimento de mais espécies no período seco. $\mathrm{Na}$ foz $\mathrm{o}$ aumento foi gradual e ocorreu em um tempo mais longo, e geralmente não acompanhado do aumento da velocidade da água.

A riqueza de espécies de peixes em assembleias locais pode ser influenciada por diferentes variáveis abióticas e bióticas que interagem em escalas espaciais e temporais diversas (MATTHEWS, 2012), sendo as variáveis abióticas consideradas particularmente importantes em sistemas lóticos, pois as características químicas e físicas do habitat influenciam a composição, distribuição e abundância de espécies e na organização e dinâmica ecológica em riachos (RICHARDS et al., 1996). Para o córrego Bebedouro, a variável temperatura da água influenciou a distribuição da riqueza de espécies (ver tabela 5). Essa variável atua diretamente no ciclo reprodutivo de peixes, influenciando na secreção de gonadotrofinas, na eliminação metabólica de hormônios e na resposta à ação de estrógenos sobre a produção de vitelogenina pelo fígado (BALDISSEROTTO, 2013). Alterações nas condições de temperatura da água também podem ser primordiais na determinação do período reprodutivo da ictiofauna, sendo que para espécies tropicais, a época da reprodução coincide com períodos de dias longos e temperaturas elevadas (MIGAUD et al., 2010), como observado nos locais averiguados nesse estudo. Canpana et al. (1995) complementam que a temperatura da água atua como fator de controle do crescimento em peixes, pois ela afeta diretamente as taxas metabólicas, o consumo de oxigênio, a atividade alimentar e a digestibilidade.

A condutividade elétrica e os sólidos totais dissolvidos também influenciaram a riqueza de espécies do córrego (ver tabela 5). Alguns trabalhos com enfoque sobre $\mathrm{o}$ impacto ambiental antrópico sobre comunidades aquáticas (Cunico et al., 2006; Alexandre et al., 2009) expuseram que o aumento da degradação ambiental leva a uma homogeneização das comunidades aquáticas, com perda de espécies nativas e aumento de espécies tolerantes à perda de qualidade da água. Neste estudo foi verificado que os locais com maiores condutividade (pontos B04 e B07) e maior quantidade de sólidos totais dissolvidos (ponto B07) no período chuvoso, apresentaram menores valores de riqueza. No período seco, a maior condutividade elétrica e a maior quantidade de sólidos totais dissolvidos foram no ponto B05, contudo a 
riqueza não foi a menor nesse ponto, podendo ser explicado pelo maior valor de vazão encontrado nesse período, que manteve a concentração de oxigênio mais elevada neste local.

Apesar de nenhuma espécie documentada nesse trabalho estar ameaçada de extinção, deve ser destacado que a ictiofauna do córrego estudado está vulnerável, como toda a diversidade de peixes da América do Sul, devido aos barramentos, a poluição, ao assoreamento e a introdução de espécies exóticas (VITULE et al., 2016). As espécies exóticas foram encontradas apenas na foz do córrego Bebedouro, provavelmente devido à presença do reservatório de Marimbondo, que o tornou em um ambiente lêntico, possibilitando que tais espécies ocupassem esse trecho causando impacto na ictiofauna nativa, assim como na estrutura das assembleias de outros organismos aquáticos, podendo apresentar consequências genéticas, taxonômicas e funcionais sobre esse ecossistema (OLDEN et al., 2004).

A ictiofauna nativa do córrego Bebedouro foi representada predominantemente por espécies de pequeno porte, sendo esse fato uma característica compartilhada com outros rios do leste brasileiro como o Paraíba do Sul (BIZERRIL e PRIMO, 2001), o Jequitinhonha (BIZERRIL e LIMA, 2005) e o Ribeira do Iguape (OYAKAWA et al., 2006).

Portanto, o presente estudo evidenciou que o córrego Bebedouro apresentou importante ictiofauna e podemos destacar que este encontra-se susceptível a diferentes impactos, sendo salientado por Nogueira et al. (2010) a importância da bacia do rio Grande, a qual pertence a bacia do córrego Bebedouro. Segundo esses autores a maioria das espécies encontradas em bacias críticas são registradas em regiões sob domínio da Floresta Atlântica e Cerrado, sendo consideradas como prioridades globais de conservação. Deve-se ainda fazer um alerta a grande ocorrência de veredas na bacia do córrego Bebedouro, o que pode ser considerado um importante local a ser estudado no futuro, podendo conter espécies desconhecidas ou raras.

\section{Agradecimentos}

Os autores agradecem a Anderson Arsentales Dalmolin, Abílio Gabriel Martins e Andreia Portella pelo auxilio nos trabalhos de campo, ao professor Dr. Osvaldo Takeshi Oyakawa (MZUSP) pela identificação de diferentes exemplares e a Fundação UNESCO - HidroEX (Projeto "Diagnóstico de Microbacias para a Sustentabilidade") que financiou a pesquisa, através do projeto TCT 17049/2011 - SECTES/FAPEMIG/HIDROEX - Diagnosis of Watersheds for Sustainability.

\section{REFERÊNCIAS}

ALEXANDRE CV, ESTEVES KE, MELO, MAMM. Analysis of fish communities along a rural-urban gradient in a neotropical stream (Piracicaba river basin, São Paulo, Brazil). Hydrobiologia, v. 641, n. 1, p. 97-114, 2009.

AMORIM NPL, GIONGO P, BELEI F, SAMPAIO WMS. Caracterização da ictiofauna do rio Santa Catarina (Bacia do São Francisco) no município de Vazante, Minas Gerais. Evolução e Conservação da Biodiversidade, v. 4, n. 1, p. 14-21, 2013.

ANA - Agência nacional de águas. HIDROWEB - Sistema de Informações Hidrológicas. Disponível em http://hidroweb.ana.gov.br/. Acesso em 15 março de 2017.

APHA. Standard Methods for The Examination of Water and Wastewater, 22nd ed. American Public Health Association, American Water Works Association, Water Environment Federation. Washington, DC, 2017. 1496 p.

APONE F, OLIVEIRA AK, GARAVELLO JC. Composição da ictiofauna do rio Vol. 18, N. 01 (2021) 
Quilombo, tributário do rio Mogi-Guaçu, Bacia do alto rio Paraná, sudeste do Brasil. Biota Neotropica, v. 8, n. 1, p. 145-159, 2008.

AZEVEDO-SANTOS VM, BRITSKI HA, OLIVEIRA C, BENINE RC. Ichthyofauna of streams of the Rio Sapucaí basin, upper Rio Paraná system, Minas Gerais, Brazil. Biota Neotropica, v. 19, n. 1, p. 1-9, 2019.

BALDISSEROTTO B. Fisiologia de peixes aplicada à piscicultura. Santa Maria: Editora UFSM, 2013. 352 p.

BENNEMANN ST, GEALH AM, ORSI ML, SOUZA LM. Ocorrência e ecologia trófica de quatro espécies de Astyanax (Characidae) em diferentes rios da bacia do rio Tibagi, Paraná, Brasil. Iheringia, Série Zoologia, v. 95, n. 3, p. 247-254, 2005.

BIRINDELLI JLO, SIDLAUSKAS BL. Preface: How far has Neotropical Ichthyology progressed in twenty years? Neotropical Ichthyolog, v. 16, n. 3, 2018.

BIZERRIL CRSF, LIMA NRW. Ictiofauna do curso inferior do rio Jequitinhonha (BA/MG) Brasil. Acta Biológica Leopoldensia, v. 27, n. 3, p. 169-173, 2005.

BIZERRIL CRSF, PRIMO PB. Peixes de água interiores do estado do Rio de Janeiro. FEMAR - SEMADS, Rio de Janeiro, 2001. $417 \mathrm{p}$.

BUCKUP PA. Sistemática e biogeografia de peixes de riachos. In: CARAMASCHI, E. P.; MAZZONI, R.; PERES-NETO, P. R. eds. Ecologia de Peixes de Riachos. Série Oecologia Brasiliensis, Rio de Janeiro, PPGEUFRJ, 1999. v. 6, p. 91-138.

CALLISTO M, MORETTI M, GOULART M. Macroinvertebrados bentônicos como ferramenta para avaliar a saúde de riachos. Revista Brasileira de Recursos Hídricos, v. 6, n. 1, p. 71-82, 2001.
CANPANA SE, MOHN R K, SMITH SJ, CHOUINARD GA. Reply: spatial implications of a temperature-based growth model for Atlantic cod (Gadus morhua) off the eastern coast of Canada. Canadian Journal of Fish and Aquatic Science, v. 52, n. 11, p. 2445-2456, 1995.

CASTRO RMC, MENEZES NA. Estudo diagnóstico da diversidade de peixes do Estado de São Paulo. In: CASTRO, R. M. C. Biodiversidade do Estado de São Paulo, Brasil: Síntese do conhecimento ao final do século XX. Winner Graph, São Paulo, 1998. p. 1-13.

CASTRO RMC. Evolução da ictiofauna de riachos Sul-Americanos: padrões gerais e possíveis processos causais. In: CARAMASHI, E. P.; MANZZONI, R.; PERES-NETO, P. R. Ecologia de Peixes de Riachos. Série Oecologia Brasilienses. Rio de Janeiro, 1999. p. 139-155.

CUNICO AM, AGOSTINHO AA, LATINI, JD. Influência da urbanização sobre as assembléias de peixes em três córregos de Maringá, Paraná. Revista Brasileira de Zoologia, v. 23, n. 4, p. 1101-1110, 2006.

DAJOZ R. Ecologia Geral. Rio de Janeiro, Editora Vozes. 1978. 472 p.

DIAS MS, ZUANON J, COUTO TB, CARVALHO M, CARVALHO LN, ESPÍRITO-SANTO HM, FREDERICO R, LEITÃO RP, MORTATI AF, PIRES THS, TORRENTE-VILARA G, VALE J, ANJOS MB, MENDONÇA FP, TEDESCO PA. Trends in studies of Brazilian stream fish assemblages. Natureza \& Conservação, v. 14, n. 2, p. 106-111, 2016.

EMATER-MG, CENEP. Projeto de Manejo Integrado dos Recursos Naturais da SubBacia do Ribeirão Frutal, EMATER-MG, CENEP, ASPARF. 2004. 21 p. 
ESGUÍCERO ALH, ARCIFA MS. The fish fauna of the Jacaré-Guaçu River basin, Upper Paraná River basin. Biota Neotropica, v. 11, n. 1, p. 2-11, 2011.

FERREIRA CP, CASATTI L. Influência da estrutura do hábitat sobre a ictiofauna de um riacho em uma micro-bacia de pastagem, São Paulo, Brasil. Revista Brasileira Zoologia, v. 23, n. 3, p. 642-651, 2006.

FISHBASE. Acesso em 23/05/17. Disponível em: http://www. fishbase.org.

FRASCÁ-SCORVO CMD, CARNEIRO DJ, MALHEIROS EB. Comportamento alimentar do matrinxã (Brycon cephalus) no período de temperaturas mais baixas. Boletim do Instituto de Pesca, v. 27, n. 1, p. 1-5, 2001.

FREDERICO RG, ZUANON J, DE MARCO P. Amazon protected areas and its ability to protect stream-dwelling fish fauna. Biological Conservation, v. 219, p. 12-19, 2018.

GERHARD P, MORAES R, MOLANDER S. Stream fish communities and their associations to habitat variables in a rain forest reserve in southeastern Brazil. Environmental Biology of Fishes, v. 71, n. 4, p. 321-340, 2004.

GONÇALVES CS, CESTARI C. Grazing of the lambari fish Deuterodon iguape is associated with mouth morphology. Zoologischer Anzeiger, v. 274, p. 127-130, 2018 .

GREGORY RS, NORTHCOTE TG. Surface, planktonic, and benthic foraging by juvenile chinook salmon (Onchorhynchus tshawytscha) in turbid laboratory conditions. Canadian Journal of Fisheries and Aquatic Sciences, v. 50, n. 2, p. 233-240, 1993.

HIGGINS CL. Spatiotemporal variation in functional and taxonomic organization of stream-fish assemblages in central Texas.
Aquatic Ecology, v. 43, n. 4, p. 1133-1141, 2009.

IUCN RED LIST UNIT. Documentation Standards and Consistency Checks for IUCN Red List Assessments and Species Accounts. IUCN, Gland, Switzerland. 2017. $65 \mathrm{p}$.

LUIZ EA, AGOSTINHO AA, GOMES LC, HAHN, N. S. Ecologia trófica de peixes em dois riachos da bacia do rio Paraná. Revista Brasileira de Biologia, v. 58, n. 2, p. 273-285, 1998.

MARCENIUK AP, HILSDORF AWS, LANGEANI F. A ictiofauna de cabeceiras do rio Tietê, São Paulo, Brasil. Biota Neotropica, v. 11, n. 3, p. 217-236, 2011.

MARQUES B, BELEI F, SAMPAIO WMS. Ictiofauna do baixo rio Manhuaçu (Bacia do baixo rio Doce). Evolução e Conservação da Biodiversidade, v. 4, n. 1, p. 32-41, 2013.

MATTHEWS W J. Patterns in freshwaterfishecology. New York: Chapman \& Hall. 2012. 756 p.

McLEAY DJ, BIRTWELL IK, HARTMAN GF, ENNIS GL. Responses of arctic grayling (Thymallus arcticus) to acute and prolonged exposure to Yukon placer mining sediment. Canadian Journal of Fisheries and Aquatic Sciences, v. 44, n. 3, p. 658-673, 1987.

MELO CE, MACHADO FA, PINTO-SILVA V. Diversidade de peixes em um córrego de cerrado no Brasil Central. Brazilian Journal of Ecology, v. 1, n. 2, p. 17-23, 2003.

MIGAUD H, DAVIE A, TAYLOR JF. Current knowledge on the photoneuroendocrine regulation of reproduction in temperate fish species. Journal of Fish Biology, v. 76, n. 1, p. 27-68, 2010 . 
NASCIMENTO BM, SMITH SW. A ictiofauna da bacia do rio Sarapuí, SP. Brasil: estrutura das assembleias e a influência de diferentes variáveis ambientais. Brazilian Journal of Aquatic Science and Technology, v. 20, n. 1, p. 29-41, 2016.

NOGUEIRA C, BUCKUP PA, MENEZES NA, OYAKAWA OT, KASECKER TP, NETO, MBR, SILVA JMC. Restricted-range fishes and the conservation of Brazilian Freshwaters. PLoS ONE, v. 5, n. 6, 2010.

OKADA EK, AGOSTINHO AA, PETRERE JR M, PENCZAK T. Factors affecting fish diversity and abundance in drying ponds and lagoons in the upper Paraná River basin, Brazil. Ecohydrology\& Hydrobiology, v. 3, p. $97-110,2003$.

OLDEN JD, POFF NLR, DOUGLAS MR, DOUGLAS ME, FAUSCH KD. Ecological and evolutionary consequences of biotic homogenization. Trends in Ecology and Evolution, v. 19, n. 1, p. 18-24, 2004. OYAKAWA OT, AKAMA A, MAUTARI KC, NOLASCO JC. Peixes de riachos da Mata Atlântica nas unidades de conservação do vale do rio Ribeira de Iguape no estado de São Paulo. São Paulo, Editora Neotrópica, 2006. 201 p.

OYAKAWA OT, MENEZES NA. Checklist dos peixes de água doce do Estado de São Paulo, Brasil. Biota Neotropica, v. 11, n. 1, p. 19-31, 2011.

PAVANELLI CS, CARAMASCHI EP. Temporal and spatial distribution of the ichthyofauna in two streams of the upper rio Paraná basin. Revista Brasileira de Biologia, v. 46, p. 271-280, 2003.

PIANA PA, GOMES LC, CORTEZ EM. Factors influencing Serrapinnus notomelas (Characiformes: Characidae) populations in upper Paraná river floodplain lagoons. Neotropical Ichthyology, v. 4, n. 1, p. 81-86, 2006.
PRINGLE CM, NAIMAN RJ, BRETSCHKO G, KARR JR, OSWOOD MW, WEBSTER JR, WELCOMME RL, WINTERBOURN MJ. Patch dynamics in lotic systems: the stream as a mosaic. Journal of the North American Benthological Society, v. 7, n. 4, p. 503-524, 1988.

REIS RE, ALBERT JS, DI DARIO F, MINCARONE MM, PETRY P, ROCHA LA. Fish biodiversity and conservation in South America. Journal of Fish Biology, v. 89, n. 1, p. 12-47, 2016.

RICCIARDI A, RASMUSSEN JB. Extinction rates of north American freshwater fauna. Conservation Biology, v. 13, n. 5, p. 1220-1222, 1999.

RICHARDS C, JOHNSON LB, HOST GE. Landscape-scale influences on stream habitats and biota. Canadian Journal of Fisheries and Aquatic Sciences, v. 53, n. 1, p. 295-311, 1996.

SANTANA WM, SAMPAIO IPEFAN, GIONGO P, DERGAM J. Ictiofauna de área prioritária para conservação, Médio São Francisco, Minas Gerais, sudeste do Brasil. Neotropical Biology and Conservation, v. 11, n. 2, p. 94-100, 2016.

SANTOS ACA, CARAMASCHI EP. Temporal variation in fish composition and abundance in a perennial tributary of the Paraguaçu river, a little know drainage in the Brazilian semi-arid region. Neotropical Ichthyology, v. 9, n. 1, p. 153-160, 2011.

SMITH WS, PETRERE JR M, BARRELLA W. Fish, Sorocaba river sub-basin, state of São Paulo, Brazil. Check List, v. 3, n. 3, p. 282286, 2007.

STRAHLER AN. Hypsometric (area-altitude) - analysis of erosion al topography. 
Geological Society of America Bulletin, v. 63, n. 10, p. 1117-1142, 1952.

TAKAHASHI ELH, ROSA FRT, LANGEANI F, NAKAGHI LSO. Spatial and seasonal patterns in fish assemblage in Córrego Rico, upper Paraná River basin. Neotropical Ichthyology, v. 11, n. 1, p. 143152, 2013.

THOMAZ AT, KNOWLES LL. Flowing into the unknown: inferred paleodrainages for studying the ichthyofauna of Brazilian coastal rivers. Neotropical Ichthyology, v. 16, n. 3, 2018.

VIEIRA TB, PAVANELLI CS, CASATTI L, SMITH WS, BENEDITO E, MAZZONI R, SÁNCHEZ-BOTERO JI, GARCEZ DS, LIMA SMQ, POMPEU PS, AGOSTINHO CS, MONTAG LFA, ZUANON J, AQUINO PPU, CETRA M, TEJERINA-GARRO FL, DUBOC LF, CORRÊA RC, PÉREZMAYORGA MA, BREJÃO GL, MATEUSSI NTB, CASTRO MA, LEITÃO RP, MENDONÇA FP, SILVA LRP, FREDERICO R, DE MARCO PA. Multiple hypothesis approach to explain species richness patterns in neotropical streamdweller fish communities. PloS One, v. 13, n. 9, 2018.

VITULE JRS, DA COSTA APL, FREHSE FA, BEZERRA LAV, OCCHI TVT, DAGA VS, PADIAL AA. Comments on Fish biodiversity and conservation in South America by Reis et al. (2016). Journal of Fish Biology, v. 90, n. 4, p. 1182-1190, 2016. 